\title{
Differences in psychosocial impact of lockdown and life satisfaction among Nigerian working adults during Covid-19
}

\author{
Sunday Itasanmi ${ }^{1^{*}}$, Violet Ekpenyong ${ }^{2}$, Solomon Ojedeji ${ }^{3}$ \\ ${ }^{183}$ Department of Adult Education, University of Ibadan, Nigeria \\ ${ }^{2}$ Department of Continuing Education, University of Calabar, Nigeria \\ * Corresponding author \\ E-mail address: itasunny2000@gmail.com \\ DOI: https://doi.org/10.21107/sml.v3i2.7912
}

\begin{tabular}{|c|c|}
\hline Article Info & A BStract \\
\hline $\begin{array}{l}\text { Keywords: } \\
\text { Psychosocial } \\
\text { impact } \\
\text { Life satisfaction } \\
\text { Covid-19 } \\
\text { Working adults } \\
\text { Nigeria }\end{array}$ & $\begin{array}{l}\text { This study assessed differences in the psychosocial impact of lockdown } \\
\text { and life satisfaction among Nigerian working adults during the Covid-19 } \\
\text { pandemic. The study was hinged on the social stress theory. Five hundred } \\
\text { and eighteen (518) Nigerian working adults participated in the study using } \\
\text { a convenience sampling technique. Two sets of questionnaires were the } \\
\text { main instruments of data collection and were complemented by in-depth } \\
\text { interview. Quantitative data collected were analyzed using one-way ANOVA, } \\
\text { while the qualitative data was thematically analyzed. Findings revealed, } \\
\text { amongst others, that livelihood activities of working adults in Nigeria were } \\
\text { significantly affected by the Covid-19 lockdown. Working adults who lost } \\
\text { jobs during Covid-19 lockdown reported a higher psychosocial impact of } \\
\text { the lockdown compared to those who stopped working, worked at home } \\
\text { and those who worked at the office during the Covid-19 lockdown in the } \\
\text { country. Based on the findings, it was recommended among others, that } \\
\text { there is a need for concerted efforts by stakeholders in the country to provide } \\
\text { enabling environment for working adults to recover and sustainably return } \\
\text { to reasonable livelihood from the shocks occasioned by Covid-19 pandemic. }\end{array}$ \\
\hline
\end{tabular}

Citation suggestion:

Itasanmi, S., Ekpenyong, V., \& Ojedeji, S. (2020). Differences in psychosocial impact of lockdown and life satisfaction among Nigerian working adults during Covid-19. Simulacra, 3(2), 237-249. https://doi.org/10.21107/ sml.v3i2.7912

Received 16 July 2020; Received in revised form 30 September 2020; Accepted 10 October 2020; Published online 25 November 2020. 


\section{Introduction}

The emergence of Coronavirus (Covid-19) in Wuhan city, China, and its spread to 216 countries with 11,425,209 confirmed cases and 534,062 deaths as of July 7, 2020 (World Health Organisation, 2020) has sparked significant crises in virtually all human activities worldwide. The Covid-19 pandemic necessitated an unprecedented measure to curtail its fast-spreading nature, and this made countries all over including Nigeria to declare lockdown aimed at restricting movements and social gatherings to stem the tide of its spread.

Nigeria, a country with a population of over 20 million and a critical regional actor in the African continent recorded its first case of Covid-19 on February 27, 2020 and declared a two week lockdown initially in three states of the federation namely, Lagos, Abuja, and Ogun on March 30, 2020, which was extended for another two weeks coupled with inter-state travel restrictions among other measures taken to slow the spread of the disease (Mogaji, 2020). Other state governments in the country at different times also declared lockdown to restrict the movements of people. Due to the lockdown, schools, businesses, and government establishments were paralyzed, and this brought about many disruptions to working adults' livelihood activities in an exceptional manner with a significant effect on their social, economic, and mental well-being (Agusi, et al., 2020).

Specifically, the Covid-19 pandemic does not only strain the Nigerian government and healthcare system, but also individuals and the larger society are equally being strained, particularly concerning their psychosocial health. This is so because virtually no one was prepared mentally or emotionally for the pandemic of this magnitude. This, therefore, could have varying degrees of psychosocial effects on different categories of people, especially the impoverished and vulnerable section of the society (Banerjee, 2020). Generally, the overall impact of Covid-19 pandemic and effect of the imposed lockdown on health, economics, employment, education, livelihood among others in Nigeria is well documented by the National Bureau of Statistics (2020) baseline report on Covid-19 impact monitoring.

According to the report, the majority of people in the country are concerned about their personal and family members' health as there is anxiety over their family members becoming ill from the disease. Also, almost half of the working adult population in Nigeria reported not being currently gainfully employed due to Covid-19 lockdown, which has implications on their livelihood (National Bureau of Statistics, 2020). Similarly, home confinement, loss of income and increased perception of health risk has the potential to produce psychosocial disorder such as irritability, anger, confusion, loneness, frustration, depression, insomnia and distress with a dire consequence on life satisfaction of people most especially working adults whose livelihood activities were truncated in a manner they never anticipated (Dubey, et al., 2020).

Psychosocial, in this context, refers to the interrelationship between psychological indicators and social factors. It pertains to the influence of social factors (relationships) on an individual's emotions, mind, or behavior and vice versa (Upton, 2013). On the other hand, life satisfaction is an individual's overall assessment of life or measurement of one's life conditions against a set standard or 
expectation at a given time, and this could either be negative or positive depending on the prevailing circumstance (Prasoon \& Chaturvedi, 2016). A working adult is taken as an individual that is 18 years and above who engages in any activity with a hopeful desire to either fulfill personal desires or family needs. While the declared lockdown confined majority of people to their homes with some still able to operate remotely, some stopped working, and some other working adults who fall in the essential service category were allowed to operate unhindered. However, several other working adults lost their jobs as a result of the Covid-19 lockdown. Therefore, it could be said that the Covid-19 lockdown conferred on working adults in the country four different job statuses, and the experience on the basis of comparison in this study.

Although the overall psychosocial impact of Covid-19 lockdown and its consequences on life satisfaction among the Nigerian population generally is still unknown, it is expected to be very substantial based on the large scale truncation of economic activities and resultant effects on people's social interaction, emotion, and well-being. Considering the high impact of Covid-19 lockdown on livelihood activities among working adults, it is likely to have a devastating consequence on their social and psychological state of mind, and this may fall short of the expected life they envisage, thereby affecting their satisfaction with life. Hence, a clear understanding of the varied psychosocial impact of Covid-19 lockdown and life satisfaction among working adults in Nigeria based on job status during the pandemic becomes pertinent to have a glaring insight into the categories of working adults hugely affected by the lockdown. This is with a view at making policy recommendations that will provide room for quick recovery from livelihood shocks occasioned by the pandemic and reduce the associated psychosocial impact which has the potential to boost working adults' life satisfaction substantially. It has been observed that there is a definite connection between workers' well-being, productivity and life satisfaction as workers who reported greater well-being are more productive and have higher life satisfaction vice-versa (Martikainen, et al., 2002; Johnson, et al., 2008).

The desire to understand the impact of the Covid-19 on people's social relationships and mental health as well as its influence on life satisfaction has led to the conduct of many studies among different categories of people in several countries of the world (Wang, et al., 2019; Fardin, 2020; Otu et al., 2020; Zhang \& Ma, 2020; Blake, et al., 2020; Bukuluki, et al., 2020; Dai, et al., 2020; UCL, 2020; Zhang, et al., 2020; White \& Boor, 2020; Briggs \& Numbere, 2020; Olaseni, et al., 2020). For instance, Zhang et al. (2020) examined the unprecedented disruption of lives and work: health, distress, and life satisfaction of working adults in China one month into the Covid-19 outbreak. The result of the study shows that those who stopped working as a result of the lockdown reported worse distress.

At the same time, the severity of the disease in participants' city predicted their life satisfaction. Also, Olaseni et al. (2020) reported the psychological distress experienced by Nigerians amid the Covid-19 pandemic. The result of the study revealed that Nigerians generally experienced various degrees of distress during the pandemic. However, there is a dearth of empirical evidence on the varied psychosocial impact of lockdown and life satisfaction during the Covid-19 period generally and working 
adults in particular in Nigeria. It thus becomes imperative to examine in clear terms the various experiences and reactions, particularly of working adults in Nigeria.

This study is guided with three research questions. Firstly, how has Covid-19 lockdown affected the livelihood activities of working adults in Nigeria? Secondly, is there any difference in the psychosocial impact of lockdown on Nigerian working adults based on job status during Covid-19? Thirdly, what is the difference in life satisfaction among working adults based on job status during Covid-19?

\section{Method}

A cross-sectional mixed-method research design was adopted for the study based on the need to have a clear understanding of the subject-matter under investigation. This approach is deemed appropriate because it entails combination of both quantitative and qualitative research methods to make inference about population that cross different sections at a particular point in time (Zheng, 2015). The participants of the study consist of working adults who are 18 years and above and involved in livelihood activities to sustain living. Five hundred and eighteen (518) Nigerian working adults selected through convenience sampling technique participated in the study. The participants were recruited through an online link-invitation generated from a webbased survey designed by the researchers on SurveyMonkey and sent to different workers' social media groups across the country. Two sets of questionnaires were used for the study: 'Workers' Psychosocial Scale (WPS) and Satisfaction with Life Scale (SWLS)'.

Section A of the questionnaires consists of demographic characteristics of the respondents and these include age, gender, marital status, educational attainment, work sector and job status during the Covid-19 pandemic lockdown period. WPS was a self-designed 5 Likert scale questionnaire consisting of 19 items to measure the variables associated with psychological and social impact of Covid-19 lockdown to working adults. On the other hand, SWLS was developed by Diener et al. (1985) and consist of 5 items adapted to assess workers' cognitive evaluations of their life satisfaction during the coronavirus lockdown. The reliability of the instruments were established through pilot testing and 0.82 and 0.81 reliability coefficients were obtained for WPS and SWLS respectively.

The questionnaires were complemented by in-depth interview (IDI) with working adults who showed interest in being contacted for interview for further discussion on the subject-matter. A total of 68 working adults participated in the interview. The interview guide centred on the impact of the Covid-19 on livelihood activities. Data were collected within two (2) weeks starting from May 2 - May 16, 2020 (over a month of initial declaration of lockdown in the country). From a total of 518 working adults that participated in the study, only 510 filled the questionnaire correctly and this formed the basis of data coding and analysis for the study. Quantitative data collected were analyzed using one-way ANOVA, while the qualitative data was thematically analyzed.

\section{Results and Discussion}

Social stress theory traces its origins to the earlier works of W.B Cannon, Adolf Meyer and Hans Selye. Cannon argued that emotionally provocative experiences such as pain and fear can increase physiological 
activity levels which help animals to cope with the experience but while often adaptive, the increase may promote the disease if not relieved. This argument by Cannon was extended by Meyer who posited that normative changes such as graduating from school or the birth of a child also have the possibility of affecting physical and mental health. Corroborating Meyer's position, Selye conducted an extensive animal experiment and concluded that a variety of physical stressors such as cold and pain can elicit the same syndrome of physiological reactions which he termed General Adaptation Syndrome (GAS). GAS is characterised in phases of alarm, resistance, and exhaustion, the last of which comes only when the animal's adaptive capacity has been overwhelmed by the stressors (McLeod \& Lively, 2007). In other words, when the body manages harmful agents from the environment by a set of generic physiological reactions, at first, the adaptation syndrome activates the body's coping mechanisms to form a resistance.

However, when there is repeated occurrence, the coping mechanisms becomes weakened and exhausted which can lead to physiological disintegration (Finsterbusch, 1982). Social stress theory provided a sociological paradigm that sees social conditions as a cause of stress for people who belong to disadvantaged groups and when it is not properly understood or managed, the stress can, in turn, cause disease (Meyer et al., 2008). Social stress theorists define stress or stressors as any environmental, social, biological, or psychological situation that requires an individual to adjust his or her ways of behaviour. Stressors according to social stress theorists are in three categories and these include Life events, chronic strains and daily hassles. Life events refer to severe changes that necessitate adjustment within a very short time e.g. natural disaster, death of love ones, loss of jobs etc.

The severity of the impact of a stressful life event is dependent on the magnitude, desirability, expectedness and timing as unexpected events are particularly distressing. Chronic strains on the hand refer to the persistent and reoccurring demands that require adaptation over a sustained length of time e.g. stressful job, poverty, environmental pollution and conflicting social roles such as combining work and family demands. While daily hassles are repetitive problems that require adjustment on daily basis e.g. traffic issues, job dissatisfaction, marital problems etc (Carr \& Unberson, 2013). The three stressors discussed above are generally seen as distinctive and discrete experiences but they overlap as they rarely occur in isolation. Also, combination of stressors on an individual at once may produce greater stress level than when they are experienced separately.

Social stress theory further stressed that the degree to which health outcomes is affected by a stressor is partly accounted for by an individual's coping resources and strategies. Coping in this context refers to people's cognitive and behavioural efforts to meet up with certain internal or external demands appraised as either taxing or beyond available resources and threatening the individual's wellbeing (Lazarus, 1990). Social psychologically-oriented stress researchers define coping resources as personal and social powers people draw upon when dealing with stress and this is categorised into two - social support and mastery or perceived control. Social support is the instrumental, emotional, and informational supports people get from others as sources or number of stressors 
becomes less important to an individual's well-being when there is a strong perception on drawing on others for support. While mastery or perceived control refers to an individual's confidence in his or her capacity to control or manage stressful situation.

It is noteworthy that people's high sense of mastery or control of the stressful situation has a significant protective effect on their health and also cushions the effect of harmful stress. However, stress reactions such as anxiety and distress can potentially drain people's stock of coping resources when they are most needed (Carr \& Unberson, 2013). Social stress theory provides a valuable theoretical framework to explain health outcomes disparities in a population as it is believed that various structural arrangements in which people find themselves greatly determine the stressors they encounter and the severity of its impact on their wellbeing (Meyer et al., 2008). Generally, social stress theory is very extensive and complex. It is selectively outlined in this study to provide a basis for explaining the differences in the psychosocial impact of lockdown and life satisfaction among working adults in Nigeria based on job status during Covid-19 pandemic

The Covid-19 pandemic has changed virtually human ways of lives notably in the way people are required to stay in their house to stop the spread of the virus with an exception of essential outings. This confinement due to the lockdown also increases people's concern about oneself and loved ones' health, livelihood activities and survival which heighten people's anxiety coupled with various media circulation filled with rumours that created an environment of uncertainty. This situation, therefore, underpins the stressful situation as depicted by the social stress theorists as one that causes an environmental, social, biological, or psychological situation that requires an individual to adjust his or her pattern of living (Lacastle, 2020). The degree to which Nigerian working adults may be affected by the psychosocial impact of lockdown during Covid-19 is dependent on their coping resources and strategies. A situation where the demand of Covid-19 far outweigh the social support and mastery to manage it may lead to high-stress level with its corresponding effects on well-being compared to when there are armful resources to draw upon. Specifically, everyone sees the coronavirus as a threat that could cause harm if contracted but the fear of being infected, losing one's job or inability to socialise with family and friends could become more harmful than the virus itself.

Likewise, people's appraisal of vulnerability and sense of coping most especially working adults whose livelihood activities have been greatly affected by the lockdown may provide the basis for understanding the dynamics involved in how stressed they are with the situation. Importantly, the identified stressors in the theory: Life events (Covid-19 pandemic, death of love ones, loss of jobs, chronic strains (stressful job, poverty, and conflicting social roles such as combining work and family demands) and daily hassles (traffic issues, job dissatisfaction, marital problems) could explain the social stress severity on working adults based on job status during Covid-19 pandemic lockdown. It is worthy of note that the impact of social stress will be more intense on working adults who experienced the three stressors together, compared to those who experienced it separately.

This section presents the results of the study based on the data collected. The findings are analyzed and presented based 
on the research questions that guided the study. The findings are as follows:

\section{RQ 1: How has Covid-19 lockdown generally affected the livelihood activities of working adults in Nigeria?}

Working adults generally opined that the Covid-19 pandemic significantly affected their livelihood activities, mostly in the area of movement, work closure, cost of transportation, and interaction with colleagues. Working adults recount the negative effect of the lockdown on their livelihood activities as thus:

Female/30yrs/Ibadan:

"As a teacher, it has prevented me from going to work, and there's a threat of losing the job."

Male/30yrs/Lagos:

"It has increased the cost of operations and the cost of our services because raw materials are not presently imported."

Female/31yrs/Akute:

"Covid-19 had a negative impact and a severe blow on my work as an entrepreneur in the sales of fashion items and health care products; there was a drastic reduction from sales (direct) indirect) to underpricing and no sales at all..."

Male/55yrs/Abuja:

"It leads to my loss of job."

\section{Male/45/Lagos:}

"Covid-19 has affected my work in many ways; interaction in the office has reduced drastically; some of my colleagues have to work remotely from home, customer's transactions have reduced, etc."

Male/38yrs/Lagos:

"Transportation has increased by 100\%. This is having a tremendous effect on my budget as transportation currently eats a colossal amount of my budget."

However, few working adults believed that Covid-19 lockdown had impacted positively on their livelihood activities as they remarked during interview sessions that:

Female/47yrs/Lagos:

"The lockdown affected my work positively. I was able to sell my products more during lockdown."

\section{Male/46/Imo:}

"Covid-19 lockdown has increased my attention to work because I work from home, and the need for me to deliver on time is with prompt expectation."

Female/25/Lagos:

"I would say it gave me the time I didn't believe I could have as I was able to pick up some jobs I have abandoned due to pressure of work."

\section{$R Q$ 2: Is there any difference in the psychosocial impact of lockdown among Nigerian working adults based on job status during Covid-19?}

Table 1 revealed that working adults who lost jobs during the outbreak had the highest psychosocial mean score of 3.0412, a standard deviation of 0.5512 and standard error of 0.1337 , while those who worked at the office had the least mean psychosocial score of 2.5039, a standard deviation of 0.6319 and standard error of 0.0626. This implied that working adults who lost jobs during the Covid-19 lockdown reported a higher psychosocial impact of the lockdown compared to those who stopped working $(x=3.0412)$, working at home $(x=2.5586)$ and those who worked at the office $(x=2.5039)$. 
Table 1: One Way ANOVA: The difference in psychosocial impact of lockdown on Nigerian working adults based on job status during Covid-19

\begin{tabular}{|c|c|c|c|c|c|c|c|c|}
\hline & \multirow{2}{*}{$\mathbf{N}$} & \multirow{2}{*}{ Mean } & \multirow{2}{*}{$\begin{array}{l}\text { Std. } \\
\text { Dev. }\end{array}$} & \multirow{2}{*}{$\begin{array}{l}\text { Std. } \\
\text { Error }\end{array}$} & \multicolumn{2}{|c|}{$95 \%$ Confidence Interval for Mean } & \multirow{2}{*}{ Minimum } & \multirow{2}{*}{ Maximum } \\
\hline & & & & & Lower Bound & Upper Bound & & \\
\hline Worked at the office & 102 & 2.5039 & 63192 & .06257 & 2.3798 & 2.6280 & 1.00 & 4.20 \\
\hline Worked at home & 217 & 2.5586 & .66877 & .04540 & 2.4691 & 2.6481 & 1.00 & 4.40 \\
\hline Stopped working & 174 & 2.7080 & .69118 & .05240 & 2.6046 & 2.8114 & 1.00 & 4.20 \\
\hline Lost job during the outbreak & 17 & 3.0412 & .55120 & .13369 & 2.7578 & 3.3246 & 2.20 & 3.90 \\
\hline Total & 510 & 2.6147 & .67365 & .02983 & 2.5561 & 2.6733 & 1.00 & 4.40 \\
\hline
\end{tabular}

Dependent variable: Psychosocial impact of lockdown scores

$R Q$ 3: What is the difference in life satisfaction among working adults based on job status during Covid-19?

Table 2 above shows working adults who lost their jobs during the outbreak had the highest life satisfaction mean score of 4.9765, a standard deviation of 1.1200 and standard error of 0.2716 , while those who worked at the office had the least mean life satisfaction score of 3.9637, a standard deviation of 1.1343 and standard error of 0.1123 . This implied that those who lost jobs during the Covid-19 lockdown reported a higher life satisfaction compared to those who stopped working $(x=4.4267)$, worked at home $(x=4.169)$, and those who worked at the office ( $x=3.9637)$.

This study revealed that the livelihood activities of working adults in Nigeria were significantly affected by the Covid-19 lockdown ordered by the government to curtail the spread of the disease, notably in the area of movement, work closure, cost of transportation, and interaction with colleagues. Other areas in which livelihood activities of working adults in the country were affected by the Covid-19 lockdown include increase in the cost of business operations as a result of border closure, low sales due to low purchasing power of the people and job loss due to downsizing engaged in by companies to reduce running cost. Due to the lockdown, banks, schools, government establishment, businesses, and other activities were forced to shut down, and people were forced to operate from home for those whose work requires working from home while those in the essential service sector were allowed to operate unhindered.

Working adults who fall in the category of essential workers had difficulty in

Table 2: One Way ANOVA:

The difference in life satisfaction among Nigerian working adults based on job status during Covid-19

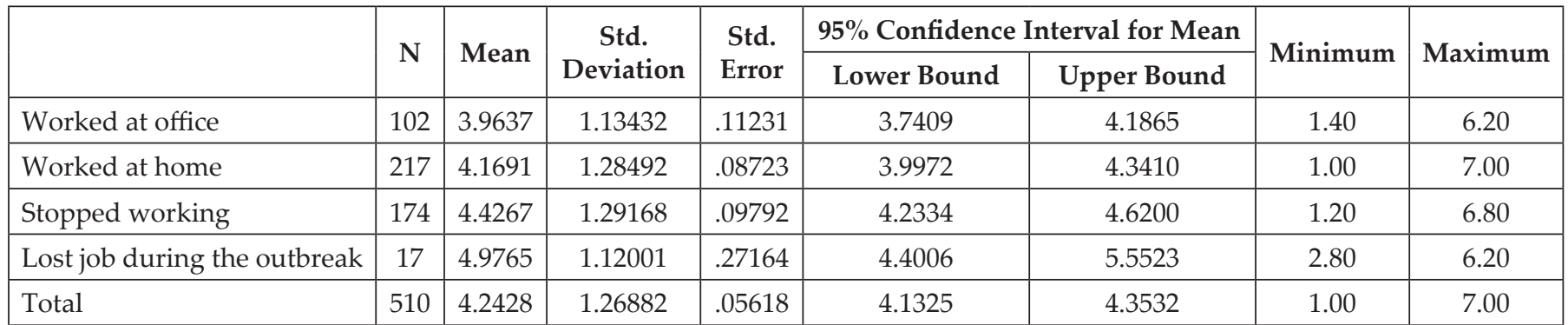

*Dependent variable: Life satisfaction 
reaching their various workplaces due to movement restrictions with an associated increase in the cost of transportation as there were few transporters to commute people to their various destinations. Also, as a result of the closure of several businesses due to the lockdown, a lot of working adults either had their salaries cut down or lost their jobs as companies take measures to remain afloat. These findings affirm the National Bureau of Statistics 2020 baseline report on Covid-19 impact, most notably on the employment and livelihood. The report revealed that $42 \%$ of working adults lost their jobs on Covid-19 related issues, and $79 \%$ of households reported a decrease in their incomes with a consequential effect on their purchasing power (National Bureau of Statistics, 2020). This result is in consonance with the findings of Ekienabor (2020) who found out among others that due to halt in livelihood activities occasioned by Covid-19, many people were really rendered penniless and prevented them from obtaining basic necessities of life.

On the comparative analysis of the psychosocial impact of the lockdown on working adults in the country based on job status during Covid-19, the study revealed that working adults who lost jobs during Covid-19 lockdown reported a higher psychosocial impact of the lockdown compared to those who stopped working, working at home and those who worked at the office. The reason working adults who lost jobs reported a higher psychosocial effect of lockdown could be attributed to the fact that losing a job takes a toll on social, psychological and biological wellbeing of an individual which could result into depression, anxiety disorders and many order somatic symptoms compared to working adults who were working from the office or stopped working because they still have their livelihood relatively secured (Greenberg, 2011).

According to Relojo-Howell (2019), when an individual loses his/her job, it does seem like the world has come to an end, and the individual feels as though their success and wealth are measured by engaging in work activities because the job serves as a source of his/her survival. The result also reinforces the psychological stress theory's assumption that when prevailing situation that an individual finds himself/herself surpasses both the internal and external resources to manage it, the individual is bound to exhibit traits that suggest psychological stress. The Covid-19 pandemic first presents a situation that creates fear and anxiety among the populace and losing job as a result of the lockdown to stop its spread compounded the situation which could worsen their sense of vulnerability and coping with situation. This has the tendency to cause a more severe social stress on them compared to working adults who stopped working, worked at home or who worked at the office, though, perhaps feel vulnerable but have a better way of coping with the situation in terms of resources.

This present study further revealed that working adults who lost their jobs during the outbreak had a higher life satisfaction compared to those who stopped working, worked at home, and those who worked at the office. The researchers attribute this results to the fact that those who lost their jobs have resigned to fate and are strategizing on the best options available to sustain their living or make required life changes possible which makes their life satisfaction higher compared to working adults who work from office or stopped working, most of whom are still in fear of losing their jobs if the situation does not improve and there is anxiety over 
their chance of contracting the deadly virus as they continue interacting with people in the course of their work.

This result underpins the submission made by International Labour Organisation (ILO) in 2020 that working from home during the Covid-19 lockdown makes it difficult for working adults to separate personal lives from work because they share spaces with spouses, partners, children or roommates and this makes work and personal life become blurred with a negative impact on their well-being. It was further stated that as a result of school and childcare programs closure, working adults were required to take on additional household chores, and this creates extra stress and difficulties in conciliating work and family responsibilities. This is more difficult for working adults in the essential services whose physical presence is required (ILO, 2020). These, therefore, significantly affect their life satisfaction based on the stress level compared with someone who has lost a job with no extra burden. This result implies that working adults who lost jobs though experienced the three stressors as indicated in the social stress theory, it appears that it is witnessed separately compared to other groups of working adults who seem to have a combined effects of the stressors with resultant impact on their well-being (life satisfaction).

\section{Conclusion}

This study assessed differences in the psychosocial impact of lockdown and life satisfaction among working adults based on job status during the Covid-19 pandemic. The findings of the study revealed that Nigerian working adults' livelihood activities in the country were significantly affected by the Covid-19 lockdown. However, while working adults who lost jobs during Covid-19 lockdown had a higher psychosocial impact of the lockdown, they had higher life satisfaction compared to those who stopped working, worked at home, and those who worked at the office during the Covid-19 lockdown in the country. Though the study participants are not nationally representative of working adults, the findings of the study provided an empirical insight into the degree at which Nigerian working adults were affected psychosocially based on job status during the Covid-19 pandemic lockdown and its corresponding impact on their life satisfaction. This is done with a view to engender a policy framework that that will help all working adults with needed support that will cushion the effect of the lockdown on their livelihood activities with consequential improvement on their psychosocial well-being and by extension life satisfaction.

Based on the findings, it was recommended that there is a need for concerted efforts by stakeholders in Nigeria to provide enabling environment for working adults to recover and sustainably return to reasonable livelihood from the shocks occasioned by Covid-19 pandemic. Also, there is a need for colossal job creation or a social safety policy to cushion the effect of job loss among working adults in the country to reduce associated psychological and social impact of job loss, which has a dire consequence on their well-being. Furthermore, there is a need to provide income support, teleworking options and home-based tools for workers who stopped working, worked at the office and working from home respectively to increase their life satisfaction and lastly, counseling/ social support services should be made more 
accessible to working adults, especially those working from office for timely reporting of mental health issues for optimal general well-being and better productivity.

\section{Declaration of Ownership}

This article is our original work.

\section{Conflict of Interest}

There is no conflict of interest to declare in this article.

\section{Ethical Clearance}

This study was approved by the institution.

\section{References}

Agusi, E. R., Ijoma, S. I., Nnochin, C. S., NjokuAchu, N. O., Nwosuh, C. I., \& Meseko, C. A. (2020). The Covid-19 pandemic and social distancing in Nigeria: Ignorance or defiance. Pan African Medical Journal, 35 (Supp 2). https://doi.org/10.11604/pamj. supp.2020.35.2.23649

Banerjee, D. D. (2020). Psychological preparedness for the Covid-19 pandemic, perspectives from India. Psychiatry Research, 288, 112999. https:// doi.org/10.1016/j.psychres.2020.112999

Blake, H., Bermingham, F., Johnson, G., \& Tabner, A. (2020). Mitigating the psychological impact of Covid-19 on healthcare workers: A digital learning package. International Journal of Environmental Research and Public Health, 17(9), 2997. https://doi.org/10.3390/ ijerph17092997

Briggs, D. C., \& Numbere, T. (2020). Covid-19 and the Nigerian child: The time to act is now. Pan African Medical Journal, 35, 1-3. https://doi.org/10.11604/pamj. supp.2020.35.2.23286
Bukuluki, P., Mwenyango, H., Katongole, S. P., Sidhva, D., \& Palattiyil, G. (2020). The socio-economic and psychosocial impact of Covid-19 pandemic on urban refugees in Uganda. Social Sciences $\mathcal{E}$ Humanities Open, 2(1), 100045. https:// doi.org/10.1016/j.ssaho.2020.100045

Carr, D., \& Umberson, D. (2013). The social psychology of stress, health, and coping. Handbook of Social Psychology, 465-487. https://doi.org/10.1007/978-94-007-67720_16

Dai, Y., Hu, G., Xiong, H., Qiu, H., \& Yuan, X. (2020, March 6). Psychological impact of the coronavirus disease 2019 (Covid-19) outbreak on healthcare workers in China. medRxiv. https://www.medrxiv.org/ content/ 10.1101/2020.03.03.20030874v1

Diener, E., Emmons, R. A., Larsen, R. J., \& Griffin, S. (1985). The satisfaction with life scale. Journal of Personality Assessment, 49(1), 71-75. https://doi.org/10.1207/ s15327752jpa4901_13

Dubey, S., Biswas, P., Ghosh, R., Chatterjee, S., Dubey, M. J., Chatterjee, S., \& Lavie, C. J. (2020). Psychosocial impact of Covid-19. Diabetes \& Metabolic Syndrome: Clinical Research E Reviews, 14(5), 779-788. https://doi.org/10.1016/j.dsx.2020.05.035

Ekienabor, E. (2020). Coronavirus (Covid-19): The lockdown strategy in Nigeria. Preprints The Multidisciplinary Preprint Platform. Retrieved July 6, 2020, from https://www. preprints.org/manuscript/202005.0201/ v1

Fardin, M. A. (2020). Covid-19 and anxiety: A review of psychological impacts of infectious disease outbreaks. Archives of Clinical Infectious Diseases, 15(Covid19):e102779. https://doi.org/10.5812/ archcid.102779

Finsterbusch, K. (1982). Psychological impact theory and social impacts. Impact Assessment, 1(4), 71-89. https://doi.org/10 .1080/07349165.1982.9725491 
Greenberg, M. (2011, October 14). Preserving mental health during unemployment. Psychology Today. https://www. psychologytoday.com/us/blog/themindful-self-express/201110/preservingmental-health-during-unemployment

ILO. (2020). Managing work-related psychosocial risks during the Covid-19 pandemic. Retrieved July 8, 2020, from https://www.ilo.org/ wcmsp5/groups/public/---ed_protect/--protrav/---safework/documents/ instructionalmaterial/wcms_748638.pdf

Johnson, J. K., Pitt-Catsouphes, M., Besen, E., Smyer, M., \& Matz-Costa, C. (2008). Quality of employment and life satisfaction: Retrieved May 20, 2020, from https://www.bc.edu/content/dam/ files/research_sites/agingandwork/pdf/ publications/IB13_LifeSatisfaction.pdf

Lancastle, D. (2020). How to cope with lockdown - a psychologist's perspective. Home I University of South Wales. https://www. southwales.ac.uk/research/researchnews/how-to-cope-with-lockdown-apsychologists-perspective/

Lazarus, R. S. (1990). Theory-based stress measurement. Psychological Inquiry, 1(1), 3-13. https://doi.org/10.1207/ s15327965pli0101_1

Martikainen, P., Bartley, M., \& Lahelma, E. (2002). Psychosocial determinants of health in social epidemiology. International Journal of Epidemiology, 31(6), 1091-1093. https://doi.org/10.1093/ ije/31.6.1091

McLeod J.D., Lively K.J. (2007) Social psychology and stress research. In: Avison W.R., McLeod J.D., Pescosolido B.A. (eds) Mental health, social mirror. Springer, Boston, MA. https://doi. org/10.1007/978-0-387-36320-2_12

Meyer, I. H., Schwartz, S., \& Frost, D. M. (2008). Social patterning of stress and coping: Does disadvantaged social statuses confer more stress and fewer coping resources? Social Science $\mathcal{E}$ Medicine, 67(3), 368-379. https://doi. org/10.1016/j.socscimed.2008.03.012

Mogaji, E. (2020). Impact of Covid-19 on transportation in Lagos, Nigeria. Transportation Research Interdisciplinary Perspectives, 6, 100154. https://doi. org/10.1016/j.trip.2020.100154

National Bureau of Statistics. (2020). Covid-19 impact monitoring. Retrieved from http://documents1.worldbank.org/ curated/en/781421591886886760/pdf/ Baseline.pdf

Olaseni, A. O., Agberotimi, S. F., Oguntayo, R., \& Akinsola, O. S. (2020). Psychological distress experiences of Nigerians during Covid-19 pandemic; The gender difference. Social Sciences $\mathcal{E}$ Humanities Open, 2(1), 100052. https:// doi.org/10.31730/osf.io/cu2h3

Otu, A., Charles, C. H., \& Yaya, S. (2020). Mental health and psychosocial wellbeing during the Covid-19 pandemic: The invisible elephant in the room. International Journal of Mental Health Systems, 14(1). https://doi.org/10.1186/ s13033-020-00371-w

Prasoon, R., \& Chaturvedi, K. R. (2016). Life satisfaction: A literature review. The Researcher- International Journal of Management Humanities and Social Sciences, 1(2), 25-32. https://theresearcherjournal. org/pdfs/01021220163.pdf

Relojo-Howell, D. (2019). How job loss impacts mental health. Retrieved from https:// www.psychreg.org/mental-healthimpact-of-job-loss/

UCL. (2020). Younger people have the lowest levels of life satisfaction under Covid-19 lockdown. UCL News. https://www. ucl.ac.uk/news/headlines/2020/may/ younger-people-have-lowest-levels-lifesatisfaction-under-covid-19-lockdown 
Upton, J. (2013). Psychosocial factors. Encyclopedia of Behavioral Medicine, 15801581. https://doi.org/10.1007/978-1-44191005-9_422

Wang, C., Pan, R., Wan, X., Tan, Y., Xu, L., Ho, C. S., \& Ho, R. C. (2020). Immediate psychological responses and associated factors during the initial stage of the 2019 coronavirus disease (Covid-19) epidemic among the general population in China. International Journal of Environmental Research and Public Health, 17(5), 1729. https://doi.org/10.3390/ijerph17051729

White, R. G., \& Van Der Boor, C. (2020). Impact of the Covid-19 pandemic and initial period of lockdown on the mental health and well-being of adults in the UK. BJPsych Open, 6(5). https://doi. org/10.1192/bjo.2020.79
WHO. (2020). Coronavirus. Retrieved July 7, 2020, from https://www.who. int/emergencies/diseases/novelcoronavirus-2019

Zhang, S. X., Wang, Y., Rauch, A., \& Wei, F. (2020). Unprecedented disruptions of lives and work: Health, distress and life satisfaction of working adults in China one month into the Covid-19 outbreak. Psychiatry Research, 288, 1-6. https://doi. org/10.1101/2020.03.13.20034496

Zhang, Y., \& Ma, Z. F. (2020). Impact of the Covid-19 pandemic on mental health and quality of life among local residents in Liaoning province, China: A crosssectional study. International Journal of Environmental Research and Public Health, 17(7), 2381. https://doi.org/10.3390/ ijerph17072381 